\title{
ARQUIVO DA FACULDADE DE DIREITO DO RECIFE: PRESERVAÇÃO E ACESSO ATRAVÉS DA EXTENSÃO UNIVERSITÁRIA
}

\author{
ARCHIVE OF FACULTY OF LAW OF RECIFE: PRESERVATION AND \\ ACCESS THROUGH UNIVERSITY EXTENSION
}

RESUMO: Este trabalho apresenta uma síntese das atividades e dos resultados obtidos pelo projeto de extensão universitária executado no Arquivo da Faculdade de Direito do Recife Pernambuco - durante os meses de abril a dezembro de 2018. Os métodos desenvolvidos envolveram a conservação preventiva, restauração e divulgação do acervo histórico presente no Arquivo do Centro de Ciências Jurídicas da Universidade Federal de Pernambuco (UFPE). Os resultados revelam a contribuição da extensão universitária para a conservação do acervo e também para a democratização dos dados e informações através da digitalização, descrição e posterior publicação dos documentos nos meios digitais. O projeto de extensão "Preservando a Memória da Faculdade de Direito do Recife: acesso ao Arquivo Histórico", dessa forma, logrou satisfatoriamente realizar ações em prol da conservação do acervo histórico e da ampliação do acesso de informações sobre uma instituição educacional de tão grande importância histórica e cultural para o Brasil.

PALAVRAS-CHAVE: Faculdade de Direito do Recife. Arquivo. Memória. Preservação.

ABSTRACT: This work presents a synthesis of activities and goals of an university extension project executed at Archive of Faculty of Law of Recife - Pernambuco - between april and december 2018. The methods developed has envolved preventive conservation, restoration and divulgation of portion of the historical collection available at the Archive of Centro de Ciências Jurídicas of Universidade Federal de Pernambuco (UFPE). The results revails a contribution of the university extension to conservate this collection and either to provide democratization of data and informations athwart digitalisation, description and subsequent publication of

\footnotetext{
${ }^{1}$ Doutor em Direito. Professor do Departamento de Teoria Geral do Direito e Direito Privado da Faculdade de Direito do Recife, Universidade Federal de Pernambuco (UFPE). Coordenador do Projeto Memória Acadêmica da Faculdade de Direito do Recife.

${ }^{2}$ Bacharel em Arquivologia e Licenciada em História pela Universidade Federal da Paraíba (UFPB). Técnica em Arquivo da UFPE, lotada no Arquivo do Centro de Ciências Jurídicas da Faculdade de Direito do Recife, Universidade Federal de Pernambuco. Vice-Coordenadora do Projeto Memória Acadêmica da Faculdade de Direito do Recife.

${ }^{3}$ Graduanda em Direito pela Faculdade de Direito do Recife, Universidade Federal de Pernambuco (UFPE). Estudante extensionista do Projeto Memória Acadêmica da Faculdade de Direito do Recife.
} 


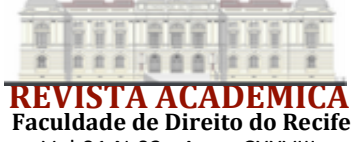

Faculdade de Direito do Recife

Vol.91 N.02 - Anno CXXVIII

documents in digital media. Thereby, the extension project "Preservando a Memória da Faculdade de Direito do Recife: acesso ao Arquivo Histórico" satisfactorily reached to take actions for the preservation of the historical heritage and for expanding access to information concerning an educational institution of such great historical and cultural importance to Brazil.

KEYWORDS: Faculty of Law of Recife. Archive. Memory. Preservation.

\section{INTRODUÇÃO}

No ano de 1827, foram criados os dois primeiros cursos jurídicos do Brasil através da Lei Imperial de 11 de agosto firmada pelo imperador D. Pedro I. Um dos cursos, na cidade de São Paulo (atual Faculdade de Direito da Universidade de São Paulo) e o outro, na cidade de Olinda (atual Faculdade de Direito do Recife que constitui hoje o Centro de Ciências Jurídicas da Universidade Federal de Pernambuco). A instauração dos primeiros cursos jurídicos oportunizou não apenas a instalação de instituições de ensino superior independentes a partir de 1828 , sendo tal anseio presente desde os tempos coloniais (BEVILÁQUA, 2012, p. 17), como também deu azo à pretensão de implantar centros culturais em prol da inovação intelectual pátria pósindependência.

Carinhosamente apelidada de "FDR", a Faculdade de Direito do Recife, representa um verdadeiro símbolo da cultura jurídica do Brasil, pois em seus longevos 191 anos de história, foi ela palco de grande agitação política, cultural e social. Celeiro de destacadas figuras da intelectualidade brasileira, sobretudo no século XIX, entre seus ex-alunos incluem-se figuras notáveis como Tobias Barreto, Joaquim Nabuco, Eusébio de Queirós, Castro Alves, Rui Barbosa, Pontes de Miranda, Clóvis Beviláqua, Raul Pompéia, Augusto dos Anjos e Epitácio Pessoa.

A importância desta instituição para a educação do Brasil tornou-se ainda mais notória com a formação da chamada "Escola do Recife", movimento intelectual surgido entre os anos de 1860 e 1880 que representou a convergência dos pensamentos e anseios histórico-nacionais da época. Como bem cita Alberto Venâncio Filho:

A realização daquela grande tarefa a que se tinham proposto as faculdades de direito, de representarem grandes centros de estudo das ciências sociais e filosóficas no Brasil, mas da qual, via de regra, se vinham omitindo ou escapando, pois trazia o movimento no seu bojo um problema de transformação de ideias no campo da filosofia, no campo do pensamento científico e no campo da crítica literária. (VENÂNCIO FILHO, 2011, p. 96)

Nota-se, portanto, a relevância da Faculdade de Direito do Recife para a história socialpolítica-cultural brasileira, sendo ela formadora de importantes vultos da vida cultural pátria e 
importante referência da história da educação no Brasil no século XIX, com especiais reflexos até os dias atuais. Nesse sentido, Pinto Ferreira em relação à Faculdade e à Escola do Recife expõe que:

A Faculdade de Direito do Recife é alma mater da Universidade e cenário de justas glórias científicas. Ela é um grande centro de debates das questões filosóficas, um cenário de discussões literárias (...). Nela sempre trepidou a pulsação de um novo saber, agigantando em muitas épocas o cenário político e jurídico do país. (FERREIRA, 1981, p. 28-29)

A partir desse curto apanhado histórico, nota-se o quão importante a Faculdade de Direito do Recife e tudo de que ela se compõe representa para a História, Direito e Memória do país. O edifício em hoje situada o acervo de sua biblioteca histórica, os documentos arquivísticos produzidos ao longo de sua existência são verdadeiras fontes históricas e que muito contribuem para a biografia jurídica, cultural e política brasileira. $\mathrm{O}$ seu acervo constitui-se como relevante espaço de guarda e preservação da memória institucional, individual e coletiva da sociedade brasileira, assim como do ensino jurídico no Brasil.

É, pois, um privilegiado e simbólico "lugar de memória" - na feliz e consagrada expressão de Pierre Nora - ao possibilitar a articulação entre produções oficiais e outros textos arquivados nas estantes com os anseios de reconstrução e conhecimento do passado e mesmo do presente: memórias de grupos, pessoas, instituições e, ainda, da própria identidade do país.

A origem dos arquivos relaciona-se, comumente, com a passagem da oralidade para a escrita, uma vez que essa transformação possibilitou a introdução de um novo elemento: o suporte. Tal suporte, ou registro do conhecimento, constituiu os primeiros acervos das primeiras instituições na Antiguidade, chamadas de "arquivos primitivos". A passagem da cultura oral para a escrita ocorreu em consequência da necessidade hu-mana de registrar, preservar e comunicar os atos, conhecimentos, sentimentos, sobretudo aqueles ligados às transações administrativas, econômicas e políticas da época.

Nesse sentido, Silva (1998, p. 45) observa que "a importância da escrita para a atividade humana levou, au-tomaticamente, à consciência de que era preciso conservar tais registros, tendo em vista uma posterior utilização". Por conseguinte, o homem, desde os primórdios da vida em sociedade, busca incessantemente alternativas para a preservação da memória, o que justifica a crescen-te notoriedade de arquivos e bibliotecas como ambientes de construção material relevante para a história e, também, de ressignificação da memória.

Pierre Nora (1993), em seu texto "Entre memória e história, problemáticas dos lugares", enfatiza o processo de ruptura entre presente e passado em decorrência da aceleração do tempo e 
assinala a importância da con-sagração de "lugares de memória" na atual sociedade desritualizada: "fala-se tanto de memória porque ela não existe mais" (NORA, 1993, p. 7). Além disso, uma contraposição entre memória e história também pode ser encontrada no texto de Nora:

A memória é a vida, sempre carregada por grupos vivos e, nesse sentido, ela está em permanente evolução, aberta à dialética da lembrança e do esquecimento, inconsciente de suas deformações sucessivas, vulnerável a todos os usos e manipulações, suscetível de longas latências e de repentinas revitalizações. A história é a reconstrução sempre problemática e incompleta do que não existe mais. A memória é um fenômeno sempre atual, um elo vivido no eterno presente; a história, uma representação do passado (NORA, 1993, p. 9).

Nora evidencia o processo de transformação dos testemunhos e memórias em narrativas, em decorrência da necessidade da transmissão de fatos da história de forma didática e docu-mentada, num processo de restabelecimento do vínculo com o passado. Portanto, tendem a conduzir novas possibilidades de interpretações de memórias, e nesse processo, à relação dos fatos históricos e cronológicos se sobrepõe o interesse pela difusão e valorização do testemu-nho. Na possibilidade de contrapor o rompimento de tradições à necessidade de memória, coloca-se a pertinência dos lugares da memória como espaços que retêm e cristalizam teste-munhos, como um ponto de referência em meio à relatividade das narrativas históricas, pois "a memória se enraíza no concreto, no espaço, no gesto, na imagem, no objeto. A história só se liga às continuidades temporais, às evoluções e às relações das coisas" (NORA, 1993, p. 9).

Convém ressaltar a relação oportuna entre a ativação da memória e a criação de arquivos históricos, identificados por Pierre Nora como suportes de lembranças que tiveram seu significado transformado ao longo do tempo: a lembrança deixa de ser uma prática social e se torna um acúmulo de informação vinculado a grupos de representatividade social.

À medida que desaparece a memória tradicional, nós nos sentimos obrigados a acumular religiosamente vestígios, testemunhos, documentos, imagens, discursos, sinais visíveis do que foi, como se este dossiê cada vez mais prolífero devesse se tornar prova em não se sabe que tribunal da história (NORA, 1993 , p. 15).

Nesta perspectiva, Nora evidencia que os lugares são essenciais para a preservação da memória e só existem porque não há outros meios: "se ainda habitássemos nossa memória, não precisaríamos consagrar-lhe lugares" (NORA, 1993, p. 19).

Assim, é possível assegurar que a memória é tanto aquela que nos é fornecida, como também a que podemos construir a partir de processos sociais. A busca do equilíbrio entre a história e memória, quando relacionado ao patrimônio, pode representar uma estratégia para 
instituições de preservação na interação com a sociedade, numa ação de integração das discussões de conservação, que incluem estratégias de gestão participativa e de proteção abrangente da memória, aproximando o cidadão de suas próprias narrativas, testemunhos e representações simbólicas.

Trabalhando a partir de tais perspectivas, estão sendo executados na Faculdade de Direito do Recife projetos de extensão universitária que tem proporcionado à preservação de acervos culturais por intermédio de atividades de conservação preventiva, descrição, digitalização e disponibilização em plataformas digitais. Além disso, promovem eventos de divulgação do patrimônio histórico e cultural da Faculdade, como minicursos, palestras e encontros temáticos. O primeiro, iniciado em 2016 e em execução até os dias de hoje, é intitulado "Memória Acadêmica da Faculdade de Direito do Recife". O segundo, iniciado em abril de 2018 e vinculado ao primeiro, foi denominado "Preservando a Memória da Faculdade de Direito do Recife: acesso ao Arquivo Histórico", sobre o qual nos deteremos a seguir, destacando as ações encetadas visando a dar visibilidade e acesso aos bens culturais que envolvem a Faculdade.

Tendo em conta tais premissas circunstanciadas, o presente artigo tem como objetivo apresentar as atividades executadas pelo projeto de extensão "Preservando a Memória da Faculdade de Direito do Recife: acesso ao Arquivo Histórico", considerando o papel da extensão universitária na formação interdisciplinar dos sujeitos envolvidos na salvaguarda do patrimônio documental de tal instituição, para além dos funcionários da própria Faculdade. Apresenta-se, ainda, relatos sobre os processos de preservação do acervo documental (conservação preventiva, descrição, digitalização e disponibilização) executados no projeto durante o ano de 2018.

\section{EXERCÍCIO DOS DIREITOS CULTURAIS ATRAVÉS DA EXTENSÃO UNIVERSITÁRIA}

A Constituição da República de 1988 foi um marco para a história do Brasil, ao permitiu a consolidação de várias garantias individuais e coletivas ao longo dos seus 30 anos de existência. No campo da educação, nota-se a firme consagração do "princípio de indissociabilidade entre ensino, pesquisa e extensão" (BRASIL, 1988) aplicado ao ensino superior. A extensão universitária é, assim, considerada juntamente ao ensino e à pesquisa, como um dos pilares do ensino superior nas universidades brasileiras. Entendeu-se por privilegiar uma visão de formação universitária na qual o ensino esteja vinculado a outras vivências e dinâmicas trazidas pela pesquisa e pela extensão. 
Cabe à extensão universitária, pois, o papel precípuo de estabelecer a relação direta com a comunidade externa à universidade. Isso fica evidenciado nas finalidades do ensino superior estabelecidas pelo artigo 43 da Lei n 9.394 de 1996, que trata das diretrizes e bases da educação nacional:

VII - Promover a extensão, aberta à participação da população, visando à difusão das conquistas e benefícios resultantes da criação cultural e da pesquisa científica e tecnológica geradas na instituição.

VIII - Atuar em favor da universalização e do aprimoramento da educação básica, mediante a formação e a capacitação de profissionais, a realização de pesquisas pedagógicas e o desenvolvimento de atividades de extensão que aproximem os dois níveis escolares. (BRASIL, 1996).

Percebe-se, portanto, que inserido no contexto do papel da extensão universitária, o projeto vivenciado no Arquivo da Faculdade de Direito do Recife teve como escopo principal realizar a integração da universidade com a sociedade através do acesso à informação e, por conseguinte, à sua própria história. Aproximar o acervo histórico da FDR à população é permitir o acesso aos bens culturais e isso se identifica com a ideia de exercício dos direitos. Ademais, pretendeu-se possibilitar através das ações da extensão conferir larga visibilidade ao acervo arquivístico e, de tal modo, colaborar para o acesso aos bens culturais ali presentes.

Os chamados "direitos culturais" são partes integrantes dos direitos humanos e além de terem sido expressamente previstos na Declaração Universal de Direitos Humanos de 1948, foram positivados pela Constituição Federal de 1988. Logo, a "constitucionalização" desses direitos pode ser percebida como uma inovação que deu a este grupo de direitos humanos uma importância e necessidade inéditas. Agora, o acesso à história, à memória e à cultura é um direito do cidadão e dever do Estado.

Nesse sentido, é possível traçar um paralelo entre a noção de exercício dos direitos humanos e as vivências das extensões universitárias. Pois, aproximar a população da universidade, pode ser uma forma primorosa de dar acesso ao exercício dos direitos culturais. Ainda mais, em se tratando de iniciativas extensionistas como o projeto "Preservando a Memória da Faculdade de Direito do Recife: acesso ao Arquivo Histórico" que teve como um de seus escopos centrais possibilitar a democratização aos bens culturais, contribuindo para a participação da sociedade na vida cultural e auxiliando na garantia dos direitos humanos e do efetivo exercício de direitos culturais.

\section{MATERIAIS E MÉTODOS}


As ações do projeto ocorreram no período de 02 de abril a 31 de dezembro de 2018, e tiveram como local de execução, predominantemente, as dependências do próprio Arquivo da FDR, atualmente, localizado no Anexo II do Centro de Ciências Jurídicas, na cidade do Recife Pernambuco ${ }^{4}$.

Tal arquivo foi criado juntamente com a própria Faculdade, sendo, desse modo, também datado de 11 de agosto de 1827. Sua instalação objetivava guardar, tratar e preservar a documentação produzida pela Faculdade e fornecer a documentação/informação aos usuários internos e externos. Desse modo, percebe-se que o arquivo tinha, inicialmente, uma função mais "administrativa", pois sua finalidade era manter informações referentes ao corpo discente, docente e administrativo.

As primeiras informações encontradas a respeito da organização do Arquivo da Faculdade de Direito do Recife datam do fim da década de 1910, quando foram realizadas as primeiras atividades de organização, na gestão do Diretor Netto Campello (BEVILAQUA, 2012). Corroborando com essa afirmação, segue um trecho do ofício $n^{\circ} 43$, de 31 de dezembro de 1923, enviado pelo Diretor Netto Campello ao Barão Ramiz Galvão, relatando tal esforço:

[...] o Arquivo da Faculdade vem sendo reorganizado desde 1917 [...]. Nunca me constou que se tivessem feito outras reorganizações no Arquivo que, impropriamente, se chamava assim, por ser muito incompleto e deficiente. O que sei é que o Arquivo reclamava colocar-se na altura dos serviços e necessidades da Faculdade e por esse motivo designei em comissão dois amanuenses - Bacharéis João Cabral de Mello Filho e Garcilaso Velloso Freire, - para lhe darem outra feição, completando-o e reorganizando-o nos moldes do excelente Arquivo do Palácio do Governo deste Estado. Mas folgo de declarar, Exmo. Sr. Barão Ramiz Galvão, que o meu objetivo foi cercado de feliz êxito, portanto os amanuenses, depois de meses de ininterrupto, pesquisador, estafante e inteligente trabalho, deram cabal desempenho à comissão, oferecendo à Faculdade um Arquivo modelar, talvez o melhor que conheço depois daquele cuja excelência assinalei. Nenhuma recompensa receberam os aludidos amanuenses senão honrosos e justos votos de louvor, que mandei consignar numa portaria, não só pelo resultado feliz da comissão, como também pelos serviços prestados a Faculdade (VEIGA, 1998, p. 20-21).

O acervo do Arquivo e a própria Faculdade de Direito ocuparam diversos endereços ao longo dos seus mais de 190 anos de existência. As constantes mudanças de sede somadas a eventos acidentais, como inundações, vivenciadas pelo Arquivo fez com que alguns documentos fossem perdidos ou extraviados (CÂMARA, 1904). Contudo, mesmo com os diversos percalços

\footnotetext{
${ }^{4}$ Endereço: Rua do Hospício, no 619, Boa Vista, Recife, Pernambuco, Brasil.
} 
o acervo possui documentos desde 1827, mostrando-se, desse modo, como um dos mais completos do Brasil.

Em $2014^{5}$, o Arquivo foi reaberto oficialmente em sua sede definitiva e atual. Através da campanha “O Direito Passa Por Aqui", na gestão da diretora Luciana Grassano, foi possível dar uma maior visibilidade e cuidado ao acervo histórico da FDR, reunindo-se uma gama de documentos, entre os quais livros de matrícula, julgamentos de exames, dossiês de alunos e professores, certidões de idade, guias de transferências, provas, termos referentes a concursos para substitutos e catedráticos, termos de posses, memórias históricas, registros de cartas de bacharéis e doutores, relatórios, correspondências, atas da Congregação, decretos, regimentos internos, programas de ensino, negativos de vidro e estatutos.

Figura 1: Fachada

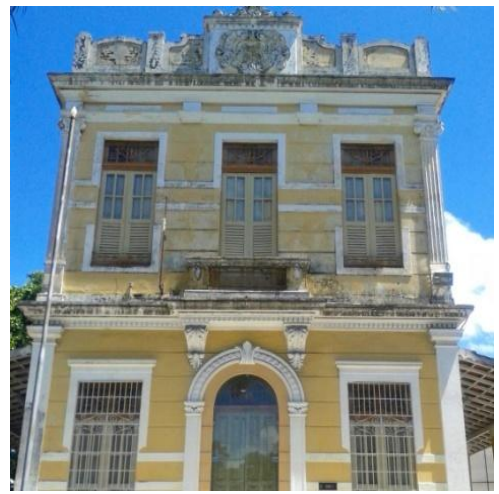

Fonte: Ingrid Rique (2015)
Figura 2: Documentos

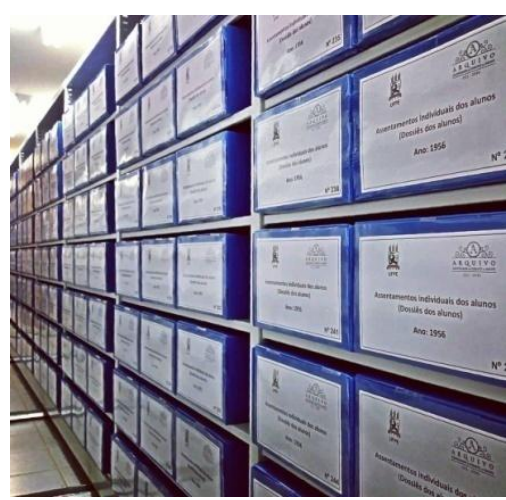

Fonte: Ingrid Rique (2018)
Figura 3: Sala doArquivo

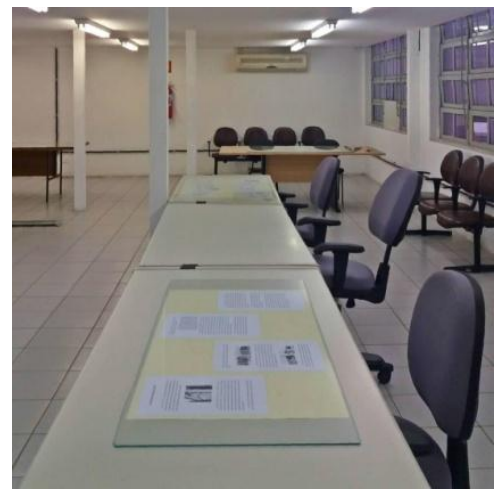

Fonte: Ingrid Rique (2018)

Nota-se, portanto, a relevância da documentação histórica que integra o Arquivo do Centro de Ciências Jurídicas da UFPE, e também, de como se mostra essencial cuidar da preservação desse acervo tão significativo para a história jurídica do Brasil. Dessa forma, a organização e preservação do Arquivo da FDR são mais do que uma necessidade, são um dever do poder público (em especial, da Universidade Federal de Pernambuco) e também da sociedade.

Foi pensando no compromisso social com a preservação e divulgação de tal acervo arquivístico que foi instituído o projeto ora em comento, congregando na execução das suas

\footnotetext{
5 A solenidade ocorreu em 11 de agosto de 2014, foi presidida pelo reitor Anísio Brasileiro e
} contou com a presença da diretora do Centro de Ciências Jurídicas, Luciana Grassano. 
atividades não apenas professores e servidores técnicos da própria Faculdade, como também - e principalmente - estudantes da UFPE de diversos cursos como Biblioteconomia, Direito e História. As ações tiveram como público-alvo a comunidade externa da UFPE (estudantes, pesquisadores ou qualquer pessoa interessada na história do ensino jurídico brasileiro nos séculos XIX e XX), e a comunidade interna da UFPE, incluindo professores, técnicos-administrativos e estudantes.

Foram desenvolvidas atividades voltadas à preservação do patrimônio documental da Faculdade de Direito do Recife, como conservação preventiva (higienização, acondicionamento e armazenamento), descrição e digitalização dos documentos, bem como outras ações que objetivaram valorizar e difundir a memória da instituição, estimulando a integração entre a universidade, a comunidade em geral e tal espaço, além de incentivar pesquisas nas áreas do Direito e História.

\subsection{DIGITALIZAÇÃO E DESCRIÇÃO DE DOCUMENTOS}

Foi realizado, inicialmente, um trabalho voltado de modo prioritário à digitalização de diversos documentos de grande relevância para o acervo da Faculdade. Afinal, as ações voltadas à descrição, digitalização e posterior disponibilização de documentos tornam o acervo acessível e útil para a sociedade em geral. A digitalização, processo de conversão de um documento para o formato digital, foi realizada por meio de dispositivo apropriado, aparelho scanner (Fujitsu Scansnap Sv600), evitando o futuro manuseamento do material. Já a descrição levou em conta os elementos formais e de conteúdo dos documentos para elaboração de aproveitáveis instrumentos de pesquisa. É importante salientar, nesse sentido, que a descrição e elaboração de instrumentos de pesquisas são as principais funções do arquivo permanente, porque é através desse material que o público tem acesso ao acervo custodiado pela instituição. É por meio desses instrumentos que o documento se torna conhecido e contextualizado, estimulando a pesquisa e o conhecimento.

A disponibilização do material digitalizado vem sendo realizada aos poucos através da divulgação nas páginas eletrônicas www.ufpe.br/memoriafdr e www.ufpe.br/arquivoccj.

\subsection{HIGIENIZAÇÃO E ACONDICIONAMENTO DE DOCUMENTOS}


Com o intuito de possibilitar a conservação preventiva do acervo, foi também realizado o esforço de higienização, acondicionamento e armazenamento corretos dos documentos. A higienização diz respeito ao processo de retirada, por meio de técnicas apropriadas, de poeira e outros resíduos. O acondicionamento refere-se à confecção de embalagens de documentos visando à sua preservação e posterior acesso. Já o armazenamento trata da guarda de documentos em mobiliário (arquivo/estantes deslizantes). Durante a vigência do projeto de extensão, foi possível a confecção de inúmeras "caixas", "envelopes" e suportes adequados à guarda dos documentos. Como exemplo, as caixas feitas de papel cartão para o acondicionamento das Atas da Congregação. Esses e outros documentos, após digitalizados, devem ser expostos ao contato humano apenas quando este for indispensável à pesquisa, visto que as ações voltadas ao correto acondicionamento do suporte objetivam conferir maior durabilidade através do isolamento e menor manuseio possível

Figura 4: Acondicionamento de documentos

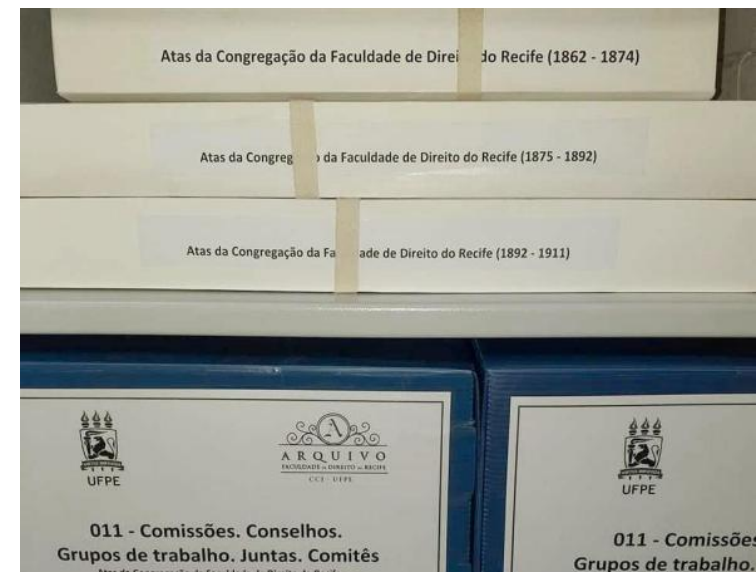

Fonte: Elizabeth Guimarães (2018)
Figura 5: Documento digitalizado

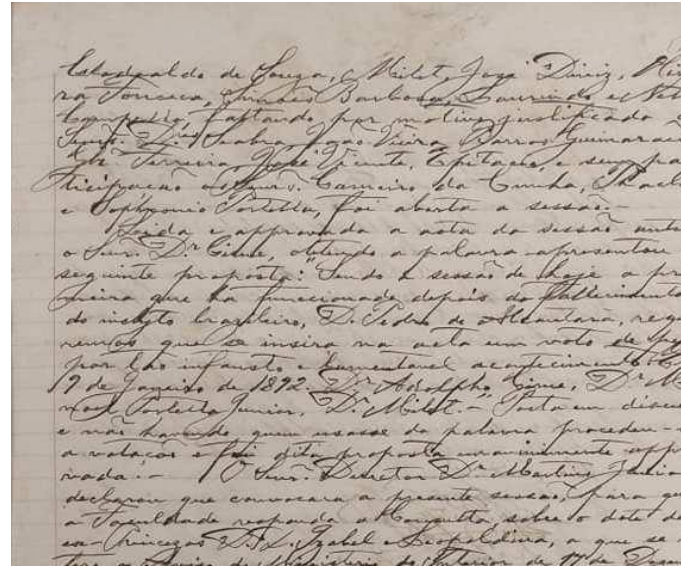

Fonte: Ingrid Rique (2018)

\subsection{CURSO DE NOÇÕES BÁSICAS DE PRESERVAÇÃO E CONSERVAÇÃO DE ACERVOS BIBLIOGRÁFICOS E ARQUIVÍSTICOS}

Nos dias 10, 11 e 12 de julho de 2018 foi realizada a oficina de "Noções básicas de preservação e conservação de acervos bibliográficos e arquivísticos" para os estudantes extensionistas do projeto, bolsistas e servidores da UFPE. Ela foi realizada no Laboratório de 
Restauração e Conservação da Faculdade de Direito do Recife - LABOR ${ }^{6}$ e orientada pelos servidores da UFPE e restauradores Angélica Borges e Gerardo Moura.

O curso teve como intuito principal proporcionar conhecimentos essenciais voltados à salvaguarda de acervos, para além de permitir momentos de reflexão e debate sobre a preservação dos documentos históricos. Dentre os participantes, estiveram alunos dos cursos de Direito, Biblioteconomia, História e servidores da própria UFPE que atuam no Arquivo e na Biblioteca.

Durante os três dias de curso houve instruções sobre modos de medição de temperatura/umidade do ambiente de acervo, além de práticas voltadas para higienização, catalogação e acondicionamento dos livros, possibilitando significativo aprendizado e debate multidisciplinares que em muito contribuíram para as atividades diárias realizadas no Arquivo do CCJ.

\footnotetext{
${ }^{6}$ Instagram: @labor_fdr.
} 


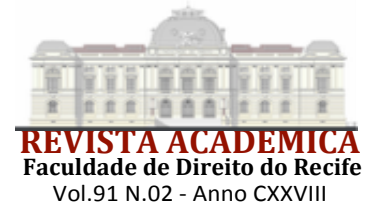

Figura 6: Atividades realizadas durante o

Figura 7: Atividades realizadas durante o curso curso

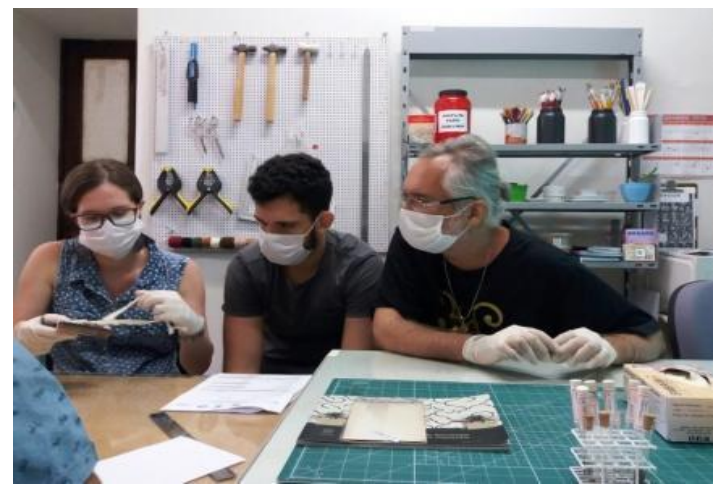

Fonte: Projeto Memória FDR (2018)

Figura 8: Higienização de documentos

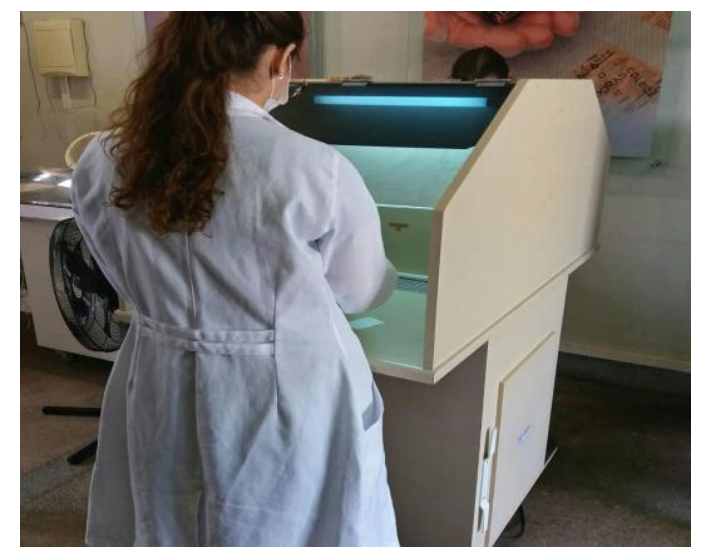

Fonte:Projeto Memória FDR (2018)

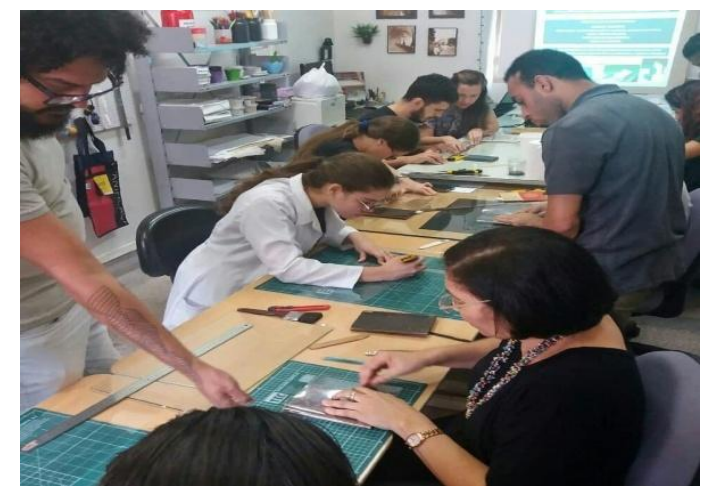

Fonte: Projeto Memória FDR (2018)

Figura 9:Participantes do curso

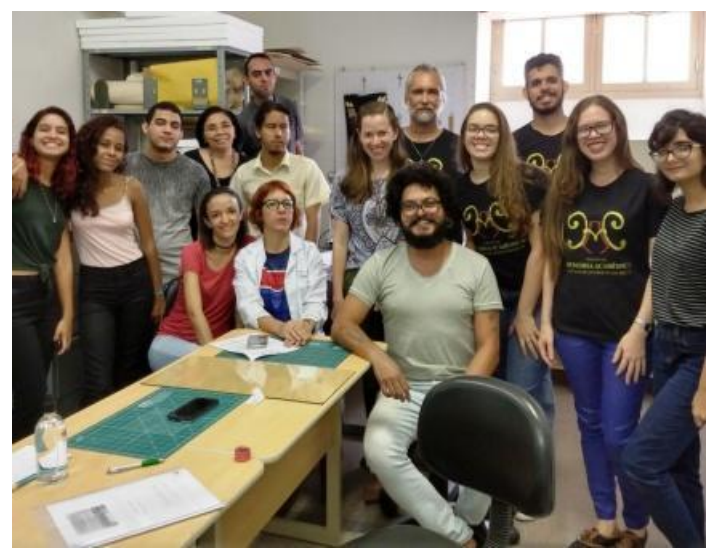

Fonte:Projeto Memória FDR (2018)

\subsection{REALIZAÇÃO DE TRABALHOS INICIAIS DE RESTAURAÇÃO DE DOCUMENTOS}

Por fim, é oportuno mencionar a execução de trabalhos iniciais de restauração de documentos, inclusive, com o auxílio dos conhecimentos adquiridos no curso realizado do Laboratório de Restauração e Conservação - LABOR. Foi possível iniciar, de tal modo, o trabalho de "descostura" de volumes referentes à "Lista geral dos estudantes matriculados na Faculdade de Direito do Recife", dos anos de 1854 a 1911, documento constantemente consultado por pesquisadores de todo o país interessados em obter informações pessoais sobre personalidades que estudaram na FDR.

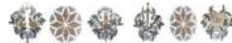

CARNEIRO FILHO, Humberto João; PEREIRA, Ingrid Rique da Escóssia; GUIMARÃES, Elizabeth da Silva. ARQUIVO DA 
Por se tratar de um trabalho delicado, o esforço consistiu em uma série de procedimentos específicos como registro fotográfico, diagnóstico, numeração, desmonte da costura e limpeza mecânica, para posterior tratamento aquosos (lavagem com água e produtos químicos), reconstituição do suporte, encadernação, acondicionamento e digitalização, utilizando-se de materiais como bisturi, cola, espátula e trincha.

Figura 10: Processo de restauração

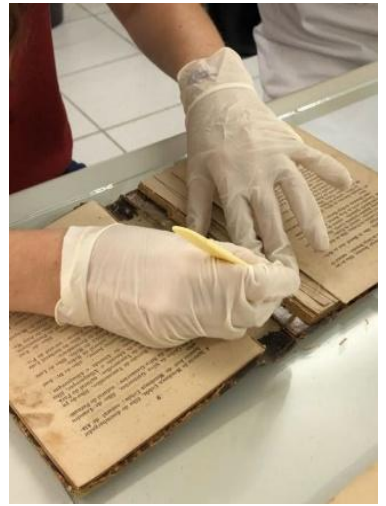

Fonte: Projeto Memória FDR (2018)
Figura 10: Processo de restauração

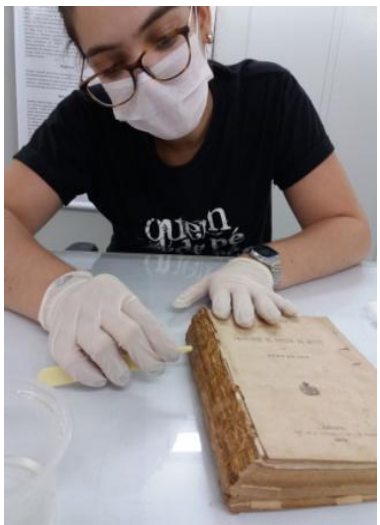

Fonte: Projeto Memória FDR (2018)

\section{RESULTADOS E ANÁLISES}

Os resultados da ação de extensão realizados no Arquivo da Faculdade de Direito do Recife revelam grande êxito para com o intuito de conservar a documentação e dar visibilidade ao patrimônio histórico ali presente. Imbuídos da intenção de realizar a conservação preventiva do acervo, foi possível realizar a higienização e acondicionamento adequados de dezenas de documentos importantes, como supracitado nos métodos utilizados.

No sentido de tornar o acervo mais acessível à sociedade, foi possível realizar a digitalização de documentos, destacando, dentre estes, todas as correspondências enviadas pela Faculdade de Direito do Recife (e Curso Jurídico de Olinda) entre os anos de 1827 a 1895 . Esse resultado pode ser analisado como de extrema relevância para a sociedade, pesquisadores e estudantes, visto que, o período em que a FDR estava instalada em Olinda (1828-1854) é escasso em documentação e dados. 
Figura 12: Correspondência digitalizada

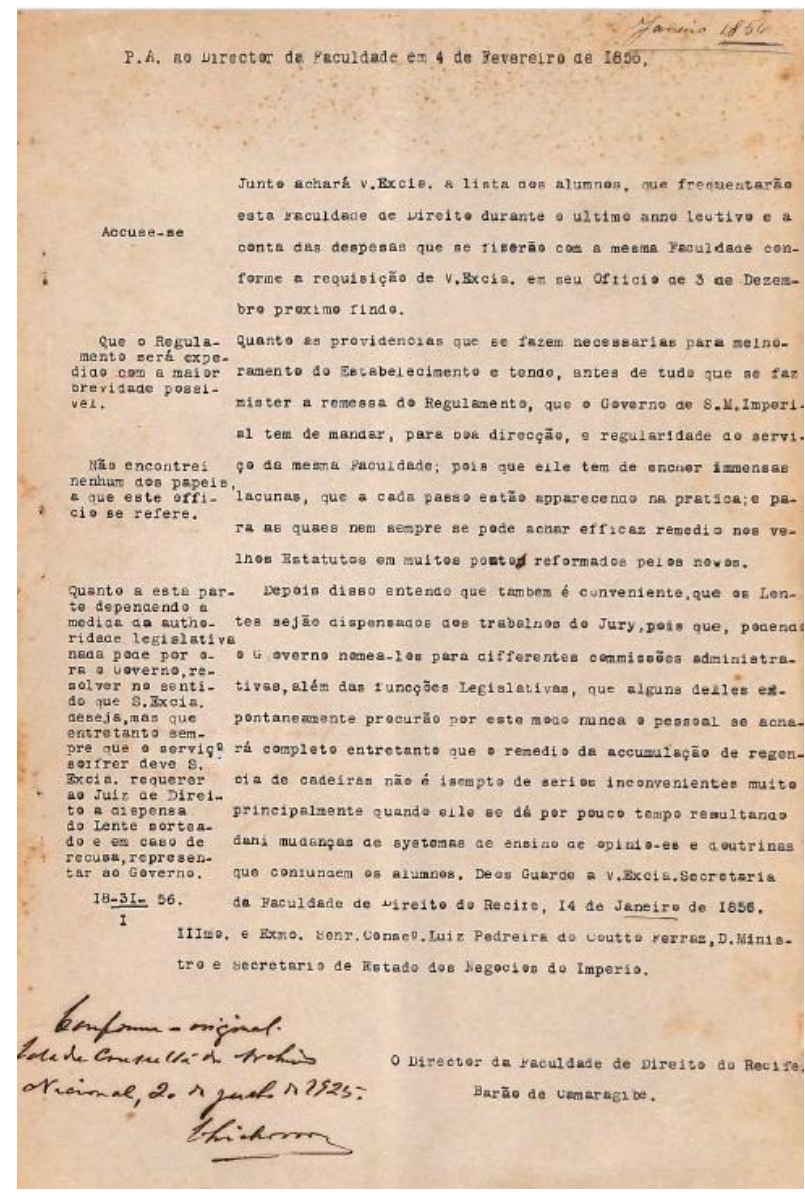

Fonte:Projeto Memória FDR (2018)

Foram também digitalizadas as "Atas da Congregação" dos anos de 1862 a 1979. Neste ponto, visando a dinamizar o acesso e a disseminação das informações, contamos com a prestimosa colaboração da Companhia Editora de Pernambuco (CEPE), através de uma parceria firmada no curso do ano de 2018, pela qual obteve-se a digitalização de tais documentos, de grande dimensão de difícil digitalização em um scanner de mesa, como o disponível no arquivo.

A digitalização tem inúmeros benefícios, como melhorar o acesso à informação, permitir o intercâmbio de acervos documentais e de seus instrumentos de pesquisa por meio de redes informatizadas, promover a difusão e a reprodução dos acervos arquivísticos não digitais, em formatos e apresentações diferenciados do original e auxiliar na preservação e na segurança dos documentos originais que estão em suportes não digitais, por reduzir seu manuseio. Logo, o trabalho da extensão universitária se mostrou extremamente frutífero neste aspecto. 
É de se frisar, também, o importante e ampliado proveito do sítio eletrônico ${ }^{7}$ e da página na rede social Facebook ${ }^{8}$, canais através dos quais foi feita a divulgação dos materiais digitalizados. Na página da rede social supracitada, se fez a divulgação de datas comemorativas, personalidades e curiosidades relativas a FDR e aos seus ilustres alunos/professores. Já no site, executou-se, além da divulgação dessas informações, a abertura do acesso direto aos documentos digitalizados em formatopdf. É a tecnologia auxiliando o trabalho de resgatar a história e memória institucional.

Inclui-se também como um valioso e expressivo resultado do trabalho da extensão universitária a realização da "II Semana Nacional de Arquivos na FDR". A iniciativa, no plano nacional é impulsionada pelo Arquivo Nacional em comemoração ao Dia Internacional dos Arquivos. Especificamente na Faculdade de Direito do Recife, o evento foi organizado pelo projeto de extensão em comento e também pelo Projeto Memória FDR no período de 4 a 16 de junho de 2018, contando com uma vasta programação voltada à reflexão sobre o patrimônio arquivístico e sobre a preservação dos acervos.

A abertura do evento deu-se com a exposição "A história da FDR em documentos", através da qual foram expostos no salão de entrada do edifício histórico da Faculdade vários documentos relativos ao cotidiano da vida acadêmica e administrativa da instituição em diversos períodos. Dentre outros documentos, foi exibido: o termo de posse do bacharel Clóvis Beviláqua datado de 12 de março de 1891; o Estatuto do Diretório Acadêmico da Faculdade de Direito do Recife do ano de 1938; a guia de transferência de Joaquim Nabuco da Faculdade de Direito do Largo de São Francisco (São Paulo) para a Faculdade de Direito do Recife em 24 de novembro de 1868; e o histórico escolar da estudante Maria Bernadette Neves Pedrosa, bacharel em 1959, e primeira mulher a ser admitida como professora da Faculdade de Direito do Recife no ano de 1965. A exposição permaneceu montada dos dias 4 a 8 de junho de 2018.

No dia 5 de junho ocorreu no Espaço Memória da FDR uma roda de conversa que tinha como temática "Arquivos, Patrimônio e Memória" que contou com a participação das palestrantes Angélica Borges ${ }^{9}$, Fabiana Dantas ${ }^{10}$ e Mônica Pádua ${ }^{11}$. As discussões foram

\footnotetext{
${ }^{7}$ https://www.ufpe.br/arquivoccj

${ }^{8}$ https://www.facebook.com/arquivodoccj/

${ }^{9}$ Técnica em restauração da FDR.
} 


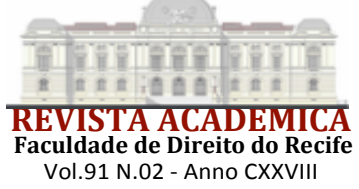

mediadas pelo Professor Humberto Carneiro ${ }^{12}$. O debate foi riquíssimo e de extrema importância para estimular o pensamento crítico em torno da temática da preservação e do valor dos patrimônios arquivísticos.

Por fim, o evento contou com duas visitas guiadas às instalações da Faculdade de Direito do Recife. A primeira ocorreu no dia 08 de junho e foi feita ao Arquivo e à Hemeroteca da FDR. A segunda, ao prédio histórico da própria Faculdade, no dia 16 de junho de 2018. Ambas as visitas foram realizadas com a supervisão de servidores e/ou extensionistas, contando com grande participação da comunidade externa à Faculdade.

Logo, com participação de estudantes, técnico-administrativos, docentes e comunidade externa, o evento da "II Semana Nacional de Arquivos na FDR" proporcionou a reflexão acerca da pesquisa e da preservação do patrimônio documental. Os objetivos do evento foram a divulgação do acervo e o estímulo à visitação, possibilitando uma aproximação efetiva entre a sociedade pernambucana e a história da Faculdade de Direito do Recife, consolidando uma imagem positiva do Arquivo enquanto lugar de memória.

Figura 13: Exposição de documentos

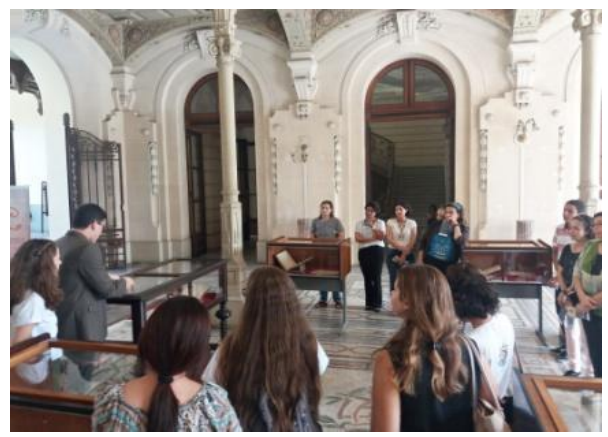

Fonte: Projeto Memória FDR (2018)
Figura 14: Roda de conversa

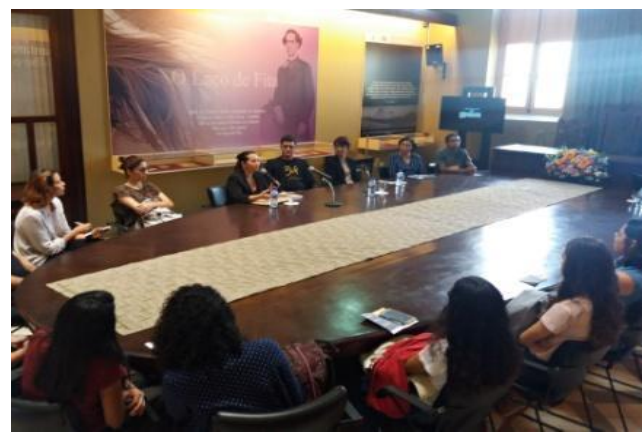

Fonte: Projeto Memória FDR (2018)

\footnotetext{
${ }^{10}$ Procuradora federal do IPHAN/PE.

${ }^{11}$ Historiadora e chefe do Memorial da Justiça do Tribunal de Justiça de Pernambuco.

12 Doutor em Direito e coordenador do Projeto Memória Acadêmica da Faculdade de Direito
} do Recife. 
Figura 15: Visita ao Arquivo

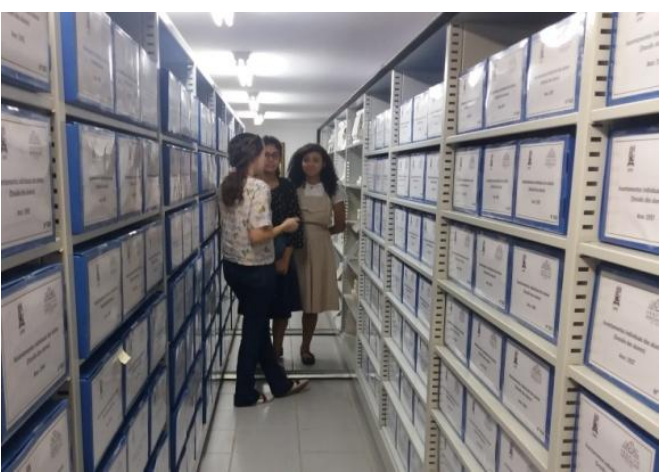

Fonte: Projeto Memória FDR (2018)
Figura 16: Visita guiada ao prédio da FDR

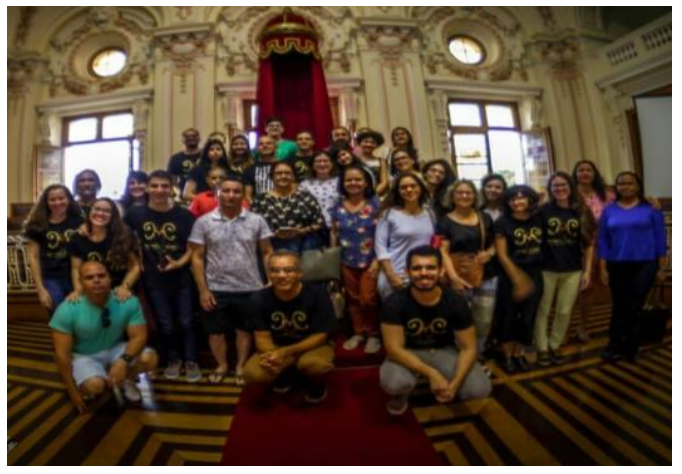

Fonte: Projeto Memória FDR (2018)

\section{CONCLUSÃO}

Este trabalho apresentou os objetivos, métodos, atividades e resultados transcorridos durante a vigência da ação extensionista universitária intitulada "Projeto Preservando a Memória da Faculdade de Direito do Recife: acesso ao Arquivo Histórico".

Apesar de todos os transcursos sofridos pelo patrimônio arquivístico da FDR, e mesmo com os anos que se manteve esquecido, o arquivo nunca perdeu a sua importância histórica, sendo percebida fielmente em projetos de extensão e ações extensionistas outras vinculadas. O seu acervo, mesmo com as devidas limitações, é sem dúvida um patrimônio inestimável da Faculdade de Direito do Recife e de todo o país. Nesta perspectiva, reafirmamos à sociedade, a importância do Arquivo da FDR para a compreensão da história jurídica do Brasil, tendo em vista a riqueza do presente espaço como detentora de memória e imensurável fonte de informação.

Por isso, a relevância e imenso sucesso das ações do projeto de extensão realizadas, com os propósitos de contribuir para a conservação e acessibilidade documental, promoção da integração da sociedade com a universidade e auxílio na garantia do acesso aos bens culturais e direitos humanos. Assim, entende-se que tal ação extensionista contribuiu para fornecer aos participantes uma formação responsavelmente cidadã aproximada aos mais elevados valores sociais, ao integrar estudantes de diversas áreas do conhecimento em um processo interdisciplinar em diálogo com a sociedade e atenta à construção de conhecimentos voltados para o desenvolvimento social e aprimoramento cultural pátrio. 
Destarte, o Arquivo da FDR sinaliza que vai além da necessidade de rememorar a história, e atende a preocupação social em dispor das informações a seus usuários, mostrando, portanto, que é fundamental para a sociedade e que pode se constituir em um espaço de execução de atividades acadêmicas em perspectiva interdisciplinar.

\section{REFERÊNCIAS}

BEVILÁQUA, Clóvis. História da Faculdade de Direito do Recife. 3. ed. Recife: Editora Universitária da UFPE, 2012.

BRASIL. Constituição (1988). Constituição da República Federativa do Brasil. Brasília: Senado Federal, 1988. Disponível em:

http://www.planalto.gov.br/ccivil_03/Constituicao/Constituicao.htm. Acesso em: 30 jun. 2019.

BRASIL. Lei no 9.394, de 20 de dezembro de 1996. Estabelece as diretrizes e bases da educação nacional. Disponível em: http://www.planalto.gov.br/ccivil_03/LEIS/L9394.htm. Acesso em: 30 jun. 2019.

CÂMARA, Phaelante da. Memória histórica da Faculdade do Recife, ano de 1903. Recife: Imprensa Industrial, 1904.

CARNEIRO FILHO, Humberto João. et al. Acesso à cultura e preservação de lugares de memória na Faculdade de Direito do Recife. Expressa Extensão, v.24, n.1, p. 06-24, jan./abr.2019. ISSN 2358-8195. Disponível em:

https://periodicos.ufpel.edu.br/ojs2/index.php/expressaextensao/article/view/14293. Acesso em: 29 jun. 2019.

FERREIRA, Pinto. História da Faculdade de Direito do Recife: Tomo 1. Recife: Universitária, 1980.

FERREIRA, Pinto. História da Faculdade de Direito do Recife: Tomo 2. Recife: Universitária, 1981.

NORA, Pierre. Entre memória e história: a problemática dos lugares. In: Projeto História, São Paulo, PUC-SP, n. 10, 1993, p. 7-28.

SILVA, Armando B. Malheiro. Arquivística: teoria e prática de uma Ciência da Informação.Porto: Afrontamento, 1998.

VEIGA, Gláucio. Origem da atual área da Faculdade de Direito do Recife. Recife: A Faculdade, 1998. (Série Cadernos da Faculdade; n. 1).

VENÂNCIO FILHO, Alberto. Das arcadas ao bacharelismo: 150 anos de ensino jurídico no Brasil. São Paulo: Editora Perspectiva, 2011. 